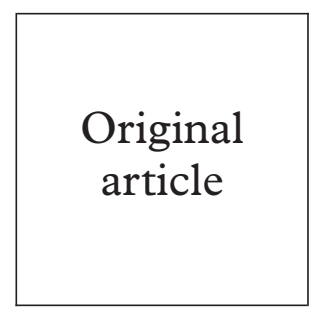

\title{
Relation between information and advice provision to male GUM clinic attendees and sexual orientation and ethnic group
}

\author{
Vivian D Hope, Christine MacArthur, David Mullis, Keith Radcliffe
}

Objectives: To examine whether the provision of advice and information to male genitourinary medicine (GUM) clinic attendees was related to their reasons for attendance, ethnicity, or sexual orientation.

Method: Cross sectional survey of men attending a large city centre GUM clinic. Data were collected using an anonymous subject completed questionnaire.

Results: Of the 302 men recruited, $72 \%$ described themselves as white and $85 \%$ reported only female sexual partners. Information and advice provision were generally found to reflect reason for attendance-for example, those attending with a concern about "an STD or urinary problem" were more likely to report advice and information on NSU/chlamydia, herpes, gonorrhoea, or syphilis than those attending without such concerns. For those attending with a concern about HIV less than half ( $42 \%$ ) reported receiving advice and information about HIV. The reasons for attendance were found to vary with ethnicity (black men were more likely to attend for a "check up," and less likely to attend about HIV or with genital warts than white men) and sexual orientation (those with male partners were more likely to attend about HIV or hepatitis B than those with only female partners); there were corresponding variations in the provision of advice and information.

Conclusions: The clinic was generally providing advice and information appropriate to the reasons for attendance and this reflected variations in such needs with ethnicity and sexual orientation. The provision of advice and information about HIV could be more comprehensive.

(Sex Transm Inf 2000;76:198-202)

Keywords: advice; male GUM clinic attendees; sexual orientation; ethnic group

\section{Introduction}

Genitourinary medicine (GUM) clinics are the main sites in the United Kingdom for the treatment of sexually transmitted infections and have a leading role in the diagnosis and care of those with HIV. These clinics are accessed by a sexually active population which is potentially at risk of HIV infection. ${ }^{1}$ Recent findings have suggested an increase in the number of people attending such clinics with sexually acquired infections. ${ }^{2}$ GUM clinic users, therefore, are an important target group for HIV and STD prevention messages. In particular, evidence suggests that sexual transmitted infections may be more common in various cultural groups with concern expressed about such infections among homosexual and bisexual men and among black Caribbeans. ${ }^{2-5}$

A previous investigation has indicated that the provision of advice and information can vary with clinic history (between old established and new clinics) and that some attendees report receiving no information or advice about safer sex or HIV even though they were attending with a relevant concern. ${ }^{6}$ The need for sexual health promotion to be targeted at, and relevant to, certain population groups has been recommended by the UK Department of Health. ${ }^{7}$ A review of sexual health service provision in the West Midlands region of the United Kingdom has indicated that there may be a need to improve sexual health services for members of the black communities ${ }^{8}$ and a community based study in the same region has noted possible issues concerning the acceptability of GUM service provision for homosexual and bisexual men, with $31 \%$ of the men surveyed reported feeling that they had encountered at least one homophobic member of clinic staff. ${ }^{9}$

This investigation has been undertaken, firstly, to further examine how GUM clinic attendees reports of the receipt of information and advice relate to their reason for attendance and, secondly, to explore any differences in the experiences of advice provision among men who have sex with men compared with heterosexual men, and among black men compared with white men.

\section{Methodology}

All male attendees of a large city centre GUM clinic were given a letter explaining the survey while in the waiting area. Sampling was undertaken over several weeks during 1996, covering all periods of the day and all days of the week that the clinic was open. Participation was offered to both new attendees and those attending for follow up. After obtaining consent and checking for previous participation those agreeing to participate were provided with a clipboard, pen, and a copy of the questionnaire which they were asked to complete during their visit, and return as they left in a sealed envelope. The questionnaire, which was anonymous, covered three main areas- 
demographic characteristics, sexual behaviour, and the provision of health advice and information. The questions on health advice were asked last and attendees were given verbal and written instructions to only complete these at the end of their visit. The completed questionnaires were coded and entered into a database. The data were analysed using sPsspct and associations examined using $\chi^{2}$ tests.

In total, 408 men were approached and questionnaires were returned by 325 (80\%). Of these 23 were excluded from the analysis either because they were returned before the end of the visit or because the questions on the back page about health advice had not been completed, making a final total of $302(74 \%)$. Those returning questionnaires before the end of their visit typically did so because they said they had attended the clinic before and knew what was going to happen to them. Those returning questionnaires without completing the back page generally did so because they had spent longer than expected at the clinic, so had insufficient time to complete the questionnaire. The demographic characteristics of these 23 did not differ from the rest of the sample.

\section{Results}

SAMPLE CHARACTERISTICS

The demographic characteristics of the sample are shown in table 1 . The sample was composed of predominately white heterosexual men under the age of 30 . The majority $(80 \%)$ were employed and all social classes were represented. About $15 \%$ had had sex with other men and one quarter were black. There were men from a diverse range of ethnic communities, but the majority of the black participants described themselves as either black Caribbean or black British.

For the majority of attendees this was not their first visit to this clinic (first ever visit 28\% (83), follow up visit $50 \%$ (151), previously visited, but attending with a new problem $22 \%$ (66)); while $21 \%$ (62) had attended other GUM clinics. The most common reported reasons for attending this present clinic were for genital warts $(90,30 \%)$, an STD $(79,26 \%)$, or check up $(67,22 \%)$; other reasons were a urinary problem $(46,15 \%)$, concern about HIV/AIDS $(36,12 \%)$ or hepatitis B vaccination $(16,5 \%)$, while $10(3 \%)$ did not specify a reason. Most of the men therefore were visiting the clinic in relation to traditional sexual health issues and not with a HIV related concern. It should be noted that those attending with a "urinary problem" may have had a sexually transmitted infection.

SEXUAL BEHAVIOUR

This was ascertained through a series of questions asking about numbers of partners and condom use. Of the 207 men reporting female sexual partners in the past 4 weeks, $66 \%$ (137) reported only one partner, $19 \%$ (41) two, $10 \%$ (21) three to five, and $4 \%$ (8) more than five. Of those responding to a question on condom use for vaginal sex, only $24 \%$ reported always using condoms and 33\% never using them. Of the 32 men reporting a male sexual partner in
Table 1 Sample characteristics

\begin{tabular}{|c|c|c|}
\hline Characteristic & No & $\%$ \\
\hline \multicolumn{3}{|l|}{ Age: } \\
\hline 19 and under & 16 & 5 \\
\hline $20-24$ & 71 & 24 \\
\hline $25-29$ & 80 & 27 \\
\hline $30-34$ & 49 & 16 \\
\hline $35-39$ & 43 & 14 \\
\hline $40-44$ & 18 & 6 \\
\hline $45-49$ & 13 & 4 \\
\hline 50 and over & 11 & 4 \\
\hline No response & 1 & - \\
\hline \multicolumn{3}{|l|}{ Marital status: } \\
\hline Single & 206 & 68 \\
\hline Divorced & 19 & 6 \\
\hline Living with partner & 40 & 13 \\
\hline Married & 30 & 10 \\
\hline Separated & 7 & 2 \\
\hline \multicolumn{3}{|l|}{ Ethnicity: } \\
\hline White, British & 201 & 67 \\
\hline White, other & 13 & 4 \\
\hline Black, Caribbean & 53 & 17 \\
\hline Black, other (mostly British) & 16 & 5 \\
\hline Asian & 11 & 4 \\
\hline Other & 4 & 1 \\
\hline No response & 4 & - \\
\hline \multicolumn{3}{|l|}{ Sexual partners: } \\
\hline Women only & 255 & 85 \\
\hline Women and men & 9 & 3 \\
\hline Men only & 36 & 12 \\
\hline No response & 2 & - \\
\hline \multicolumn{3}{|l|}{ How they fill their time: } \\
\hline Employed & 205 & 68 \\
\hline Unemployed & 53 & 18 \\
\hline Student & 31 & 10 \\
\hline "Houseperson" & 4 & 1 \\
\hline Non-worker & 7 & 2 \\
\hline No response & 2 & - \\
\hline \multicolumn{3}{|l|}{ Social class: } \\
\hline $\mathrm{I} / \mathrm{II}$ & 84 & 28 \\
\hline IIInm & 38 & 13 \\
\hline IIIm & 61 & 20 \\
\hline IV/V & 46 & 15 \\
\hline Unknown (inc students) & 73 & 24 \\
\hline
\end{tabular}

the past month $50 \%$ (16) reported one partner, $25 \%$ (eight) two, $16 \%$ (five) three to five, and $9 \%$ (three) more than five. Of those responding to a question on condom use for anal sex with men, 53\% reported always using condoms and only $11 \%$ never using them.

\section{HEALTH ADVICE}

The questionnaire contained a series of questions about advice or information given while in the clinic. The attendees were first asked if they had been given advice by members of various staff groups and if this advice was easy to understand. Eight attendees had not seen a doctor $(3 \%)$ and another $13(4 \%)$ had seen a doctor but received no information or advice. The rest all reported receiving information and advice from the doctor they had seen: $77 \%$ (229) had understood all of it, $47(16 \%)$ understood some of it, only one $(0.3 \%)$ did not understand any of it.

Over half $(175,60 \%)$ of the attendees reported information and advice from a nurse and understood it all, and a further $23(8 \%)$ reported receiving information and advice but understood only some of it. No attendee reported receiving information or advice from a nurse that they did not understand at all. Fifty one $(17 \%)$ attendees saw a nurse but received no information or advice, and 44 (15\%) did not see a nurse.

Just under half $(140,48 \%)$ of the attendees did not see a health adviser and 27 (9\%) saw one but reported receiving no information or advice. 
The remainder reported seeing a health adviser who gave information or advice: 108 (37\%) understood all of this and $23(5 \%)$ some of it.

Using a fixed response question to which more than one answer could be given, the attendees were then asked whether they had received any information or advice on a range of particular sexual health issues from anyone at the clinic. The following responses were obtained: using condoms $21 \%$ (64), genital warts $21 \%(63)$, HIV/AIDS $15 \%(46)$, NSU/ chlamydia 13\% (40), hepatitis B 7\% (21), sexual problems $7 \%$ (21), herpes 5\% (16), partner's problems $5 \%$ (14), contraception $4 \%$ (12), gonorrhoea $4 \%$ (12), relationships $4 \%$ (11), syphilis $3 \%$ (nine), and on other issues $4 \%$ (five), while $28 \%$ (84) reported no information or advice.

The attendees were asked further questions about specific discussions they may have had with someone at the clinic about sexual health issues: "Did you talk with anyone about": your sexual relationships ( $32 \%$ (98) did); using condoms (26\% (78) did); how to avoid infections

Table 2 Reasons for attendance at clinic compared with information and advice received

\begin{tabular}{|c|c|c|c|c|}
\hline \multirow{2}{*}{$\begin{array}{l}\text { Reason for } \\
\text { attendance at } \\
\text { clinic }\end{array}$} & \multirow[b]{2}{*}{$\begin{array}{l}\text { Information or } \\
\text { advice about: }\end{array}$} & \multicolumn{2}{|c|}{ No receiving information or advice (\%) } & \multirow[b]{2}{*}{$p$ Value } \\
\hline & & $\begin{array}{l}\text { Attending for } \\
\text { this reason }\end{array}$ & $\begin{array}{l}\text { Not attending } \\
\text { for this reason }\end{array}$ & \\
\hline \multicolumn{5}{|l|}{ Warts } \\
\hline & Warts & $58(64)$ & $5(2)$ & $<0.0001$ \\
\hline & Using condoms & $23(26)$ & $41(19)$ & ns \\
\hline & NSU/chlamydia & $6(7)$ & $34(16)$ & 0.0280 \\
\hline & HIV & $5(6)$ & 41 (19) & 0.0023 \\
\hline & Hepatitis B & $1(1)$ & $20(9)$ & 0.0093 \\
\hline & Herpes & $2(2)$ & $14(7)$ & ns \\
\hline & Gonorrhoea & $0-$ & $12(6)$ & 0.0130 \\
\hline & Syphilis & $0-$ & $9(4)$ & 0.0393 \\
\hline & Total & 90 & 212 & \\
\hline \multicolumn{5}{|c|}{ STD or urinary problem } \\
\hline & Warts & $7(6)$ & $56(31)$ & 0.0174 \\
\hline & Using condoms & $28(23)$ & $36(20)$ & ns \\
\hline & NSU/chlamydia & $25(21)$ & $15(8)$ & 0.0016 \\
\hline & HIV & $16(13)$ & $30(12)$ & ns \\
\hline & Hepatitis B & $6(5)$ & $15(8)$ & ns \\
\hline & Herpes & $11(9)$ & $5(3)$ & 0.0150 \\
\hline & Gonorrhoea & $9(7)$ & $3(2)$ & 0.0130 \\
\hline & Syphilis & $6(5)$ & $3(2)$ & ns \\
\hline & Total & 120 & 182 & \\
\hline \multicolumn{5}{|l|}{ Check up } \\
\hline & Warts & $7(10)$ & $56(24)$ & 0.0174 \\
\hline & Using condoms & $16(24)$ & $28(12)$ & ns \\
\hline & NSU/chlamydia & $13(19)$ & $27(11)$ & ns \\
\hline & HIV & $17(25)$ & $29(12)$ & 0.0882 \\
\hline & Hepatitis B & $6(9)$ & $15(6)$ & ns \\
\hline & Herpes & $6(9)$ & $10(4)$ & ns \\
\hline & Gonorrhoea & $3(4)$ & $9(4)$ & ns \\
\hline & Syphilis & $5(7)$ & $4(2)$ & 0.0144 \\
\hline & Total & 67 & 235 & \\
\hline HIV & Warts & $1(3)$ & $62(22)$ & 0.0044 \\
\hline & Using condoms & $5(14)$ & $59(21)$ & ns \\
\hline & NSU/chlamydia & $2(6)$ & $38(14)$ & ns \\
\hline & HIV & $15(42)$ & $31(14)$ & $<0.0001$ \\
\hline & Hepatitis B & $4(11)$ & $17(4)$ & $\mathrm{ns}$ \\
\hline & Herpes & $1(3)$ & $15(6)$ & ns \\
\hline & Gonorrhoea & $2(6)$ & $10(4)$ & ns \\
\hline & Syphilis & $1(3)$ & $8(3)$ & ns \\
\hline & Total & 36 & 266 & \\
\hline \multicolumn{5}{|l|}{ Hepatitis B } \\
\hline & Warts & $1(6)$ & $62(22)$ & ns \\
\hline & Using condoms & $3(19)$ & $61(22)$ & ns \\
\hline & NSU/chlamydia & $1(6)$ & $39(14)$ & ns \\
\hline & HIV & $5(31)$ & 41 (14) & ns \\
\hline & Hepatitis B & $11(69)$ & $10(3)$ & $<0.0001$ \\
\hline & Herpes & $0-$ & $16(6)$ & ns \\
\hline & Gonorrhoea & $0-$ & $12(4)$ & ns \\
\hline & Syphilis & $1(6)$ & $8(3)$ & ns \\
\hline & Total & 16 & 286 & \\
\hline
\end{tabular}

Note: Those attending with a concern about a urinary problem (which may have been an STD) were grouped with those attending with a concern about an STD. passed on by sex (21\% (64) did); safer sex (21\% (62) did); how HIV might be passed on by sex ( $8 \%(24)$ did), and how HIV might be passed on by drug use (6\% (17) did). There were $57(19 \%)$ attendees who indicated they wanted more advice. This was about a diverse range of topics.

Attendees were asked if they had been given condoms to take away: 95 (31\%) were and 49 $(16 \%)$ said they would use these. One further question was asked, "Will your visit to the clinic today make any difference to your sexual activities?": $124(42 \%)$ said that it would, $73(25 \%)$ said it might, and $70(23 \%)$ said it would not; the remaining $31(10 \%)$ were unsure.

REASON FOR ATTENDANCE AND HEALTH ADVICE To obtain an indication of how advice and information related to the concerns that lead to a clinic visit, reasons for attendance were compared with reports of information or advice given (table 2). This indicates that advice and information are closely related to reason for attendance. However, attendees did not always report advice about problems they were attending with: in particular about one third of those attending about warts reported being given no information or advice about warts, and less than half of those attending with a concern about HIV reported being given HIV information or advice.

SEX OF PARTNERS, REASON FOR ATTENDANCE, AND HEALTH ADVICE

Men who reported any male sexual partners were compared with those who reported only female sexual partners. Differences were found in the reason for the visit: those reporting sex with men were more likely to be attending with a concern about HIV (22\% (10 of 45) compared with $10 \%$ of those who did not have sex with men (26 of 255), $\chi^{2}=5.239$, $\mathrm{p}=0.0221)$, or for hepatitis B vaccination $(24 \%$ (11 of 45) compared with $2 \%$ (four of 255 ), $\chi^{2}$ $=42.140, \mathrm{p}<0.0001)$. There were no differences for any other reasons.

There were no differences between these two groups on advice from particular categories of staff or the extent to which this advice was understood. There were differences however in the types of information or advice; men who had sex with men were more likely to report receiving information or advice on HIV/AIDS (29\% (13 of 45 ) compared with $13 \%$ of those not reporting sex with men (33 of 255), $\chi^{2}$ $=7.493, \mathrm{p}=0.0062)$; on hepatitis B (29\% (13 of 45) compared with $3 \%$ (eight of 255$), \chi^{2}$ $=38.964, \mathrm{p}<0.0001)$; and on gonorrhoea $(11 \%$ (five of 45 ) compared with $3 \%$ (seven of 45 ), $\chi^{2}$ $=6.972, \mathrm{p}=0.0214)$. The were no other differences relating to information or advice.

The only difference between these two groups in their responses to the questions about discussions with clinic staff on specific sexual health issues was that those who had male sexual partners were more likely to report talking about "how HIV might be passed on by sex" (nine $(21 \%)$ of those who had male sexual partners compared with $15(7.0 \%)$ of those who had only female sexual partners $\chi^{2}$ 
$=8.196, \mathrm{p}=0.0085)$. There were no differences on whether the clinic visit would make any difference to sexual activities, whether condoms were given, or whether they would like to have had more advice at the clinic.

The sexual behaviour of the two groups was compared by using an aggregate measure of condom use for penetrative sex, based on the answers to the questions on this for vaginal sex and for anal sex (with men). Seventeen (77\%) of the men with male sexual partners reported consistent condom use for penetrative sex in the past 4 weeks, compared with 72 (34\%) of the men who only had female sexual partners $\left(\mathrm{n}=232, \chi^{2}=15.563, \mathrm{p}=0.0001\right)$.

ETHNIC GROUP, REASON FOR ATTENDANCE AND HEALTH ADVICE

In this section black and white attendees who had female partners only were compared (there was only one black attendee who had sex with men). Differences were found in the reasons for visiting the clinic: black attendees were more likely to attend for a check up (36\% (24 of 67) compared with $18 \%$ (31 of 169), $\chi^{2}$ $=8.199, \mathrm{p}=0.0042)$; and less likely to attend for genital warts (11\% (seven of 67) compared with $40 \%$ (68 of 169$\left.), \chi^{2}=19.638, p<0.0001\right)$ or with a concern about HIV/AIDS (5\% (three of 67) compared with $14 \%$ (23 of 169), $\chi^{2}$ $=4.081, \mathrm{p}=0.0434)$. There were no differences in the numbers attending for other reasons.

There were no differences between these two groups on advice from particular categories of staff or its comprehension. There were differences however in the types of information or advice given, with black attendees more likely to report advice on gonorrhoea ( $8 \%$ (five of 67 ) compared with $1 \%$ (one of 169 ), $\chi^{2}=9.142$, $\mathrm{p}=0.0077$ ); on syphilis ( $6 \%$ (four of 67) compared with $1 \%$ (one of 169), $\chi^{2}=6.693$, $\mathrm{p}=0.0238)$; on sexual problems $(12 \%$ (eight of 67) compared with $4 \%$ (seven of 169), $\chi^{2}$ $=4.902, \mathrm{p}=0.0319)$; and less likely to receive advice on genital warts (3\% (two of 67) compared with $31 \%$ (52 of 169), $\chi^{2}=20.989$, $\mathrm{p}<0.0001)$. There were no other differences in relation to information or advice.

There were a number of differences between the groups in their responses to the questions about discussions with clinic staff about particular sexual health topics. Black attendees were more likely to have talked about safer sex $(39 \%$ (23 of 59) compared with $20 \%$ of white attendees ( 23 of 148), $\chi^{2}=8.430, p=0.0037$ ); about how to avoid infections passed on by sex $(40 \%$ (23 of 57) compared with $22 \%$ (32 of 149), $\chi^{2}$ $=7.504, \mathrm{p}=0.0062)$; and about how HIV might be passed on by drug use $(17 \%$ (nine of 54 ) compared with $4 \%$ (six of 145), $\chi^{2}=8.862$, $\mathrm{p}=0.0056)$. There were no differences in talking about their sexual relationships, using condoms, or how HIV might be on by sex.

There was no difference between the two groups in whether the visit to the clinic today would make any difference to their sexual activities. However, more of the black attendees were given condoms to take away (29 (48\%) compared with $49(30 \%)$ white attendees, $\chi^{2}$ $=5.976, \mathrm{p}=0.0145, \mathrm{n}=224)$; and were more likely to want more advice (17 (30\%) compared with $29(18 \%)$ of white attendees, $\chi^{2}$ $=4.055, \mathrm{p}=0.0440, \mathrm{n}=220$ ).

The sexual behaviour of the two groups was compared in terms of condom use for vaginal sex. Only $11(21 \%)$ of the black attendees reported consistent condom use compared with $60(43 \%)$ of the white attendees $(n=194$, $\left.\chi^{2}=7.888, p=0.0500\right)$.

\section{Discussion}

The attendees were visiting the clinic for a variety of reasons and received advice and information on a wide range of subjects, from sexual problems to herpes. As expected the information and advice received clearly reflected reason for attendance. The giving of information and advice on condom use and HIV, however, was not comprehensive, with less than half of those attending with a concern about HIV reported receiving information and advice on HIV, and less than a fifth on using condoms. In fact, a lower number of those attending with an HIV related concern received information or advice on condom use than those attending for other reasons. These findings from this current study are in general agreement with those of a previous studies, ${ }^{6910}$ indicating that the giving of information or advice related to HIV could be more comprehensive.

The receipt of advice was further explored in this study by asking attendees about discussions they had with clinic staff. Around one quarter of attendees had such discussions about condom use, safer sex, and how to avoid infections passed on by sex, but fewer than one in 10 reported talking about the transmission of HIV by either sex or by drug use, further suggesting that there was little direct discussion of HIV. It should be noted that the clinic, although large and based in metropolitan area, is in a region of the United Kingdom with a relatively low HIV prevalence. ${ }^{11}$

A survey of the staff about the giving of information and advice at the same clinic found this to be fairly comprehensive, with the majority of staff reporting giving advice and information on a range of topics including HIV. ${ }^{12}$ Staff practice generally reflected the clinic's policy on providing advice and information to patients which can be summarised as follows. There is no written policy as to when and which advice should be given to patients by doctors. It is expected that clinicians will use personal judgment and initiative in deciding what is appropriate in a particular case. In terms of people diagnosed as having infections that are definitely sexually transmitted, such as gonococcal or chlamydial infections, it would certainly be expected that doctors would give information on preventing reinfection. Patients with chlamydial and gonococcal infections are in any case automatically referred to health advisers who do have written policies indicating that information about health promotion and prevention of further episodes of sexually transmitted infections should be given.

These findings suggest some discrepancy between the provision of advice and information by staff and reports of receipt by 
attendees. Staff reports of what information and advice they provide may reflect what they can, and would hope to give, rather than what might actually occur in practice, especially in a large and very busy clinic. There may been misunderstandings about who was going to give the information or advice, or there may have been other procedural problems at the clinic. There are also various reasons why advice provision may be misreported by attendees. Some attendees may not have understood the information or advice given, or may have actually been given it but not assimilated it; while others may not have articulated their HIV concern to the clinic staff or may have appeared to be already well informed and so no information or advice was provided. A combination of these factors is the most probable explanation of attendees not always reporting the receipt of appropriate information and advice. However, attendees generally found most of the information or advice that they were given by the different clinic staff easy to understand, indicating that medical, nursing, and health advising staff were effective in giving information in clear and appropriate ways.

This study has not examined the methods used to convey information and advice, but an investigation into counselling in relation to HIV has suggested that an interview style of approach, involving an active two way communication process, is the most effective method. ${ }^{13}$ Such methods are however time consuming.

Reasons for attendance at the clinic varied with both sexual orientation and ethnicity. The variations in reason for attendance were found to reflect known differences in sexual health. The majority of HIV infections reported in the United Kingdom are among men having sex with other men and the highest prevalence of HIV is also found in this group. ${ }^{11}{ }^{14}$ In $19968 \%$ of male diagnoses at GUM clinics in England were reported as "homosexually acquired"; however, $62 \%$ of new presentations of HIV and AIDS infections, $52 \%$ of attendance for hepatitis $B$ vaccination, around a fifth of attendances for gonorrhoea and syphilis were by men who had sex with other men. ${ }^{2}$ High levels of sexually transmitted infections have also been reported among Afro-Caribbean men. ${ }^{3-5}$ The variations in the reported reason for attendance are likely to reflect actual variations in health and are therefore an expression of sexual health need. This is supported by the findings from this current study that suggest differences in sexual risk behaviours between the subgroups-for example, black attendees were more likely to report unprotected penetrative sex.

The advice and information that attendees from the subgroups reported receiving generally reflected their reasons for attendance. The clinic was therefore generally addressing the expressed sexual health information and advice needs of these subgroups - namely, homosexual/bisexual men and men from ethnic minority communities. The differences in the sexual health needs between the subgroups may however reflect "cultural" variations between these population subgroups. There may be cultural variations in behavioural norms and the perceptions of the risks and costs associated with genitourinary infections - for example, having "a dose of the clap" may be more stigmatised in some cultures than others. There may also be cultural differences in the understanding of sexual health and the associated language, "a check up" may have various meanings among the different subgroups. Cultural variations will need to be acknowledged during the process of advice and information giving if this is to be effective; however, these were not examined in this study.

This investigation has shown that further more detailed studies are necessary. The quantitative type of approach adopted here will need to be supplemented by qualitative methods, such as interviews with both staff and attendees. Interviews have recently been successfully used to elicit users views on a GUM clinic. ${ }^{15}$ This approach could be adopted for use in studies of the provision of advice and information, particularly in examining cultural appropriateness. Further investigations will also need to involve a range of clinics in various setting with different histories.

We would like to thank all those who participated in the study. We are also grateful to the clerical staff who undertook the data entry, and to the West Midlands NHS Executive for funding this work

Contributors: VH was involved with the design of the study, carried out the fieldwork, undertook the analyses, and coordinated the writing of the paper; CM helped with the design of the study, assisted with the analysis, and contributed to the writing of the
paper; DM and KR assisted with the design of the study, supported the fieldwork, and contributed to the writing of the paper.

1 Johnson AM, Wadsworth J, Wellings K, et al. Sexual attitudes and lifestyles. London: Blackwell Scientific Publications, 1994.

2 Simms I, Hughes G, Swan AV, et al. New cases seen at genitourinary medicine clinics: England 1996. CDR 1998; 8(Suppl):S1-11.

3 De Cock KM, Low N. HIV and AIDS and other sexually transmitted diseases, and tuberculosis in ethnic minorities in the United Kingdom. Is surveillance serving its purpose? BMF 1997;314:1747-51.

4 Lacey JN, Merrick DW, Bensley DC, et al. Analysis of the sociodemography of gonorrhoea in Leeds, 1989-93. BMF 1997;314:1715-18.

5 Low N, Daker-White G, Barlow D, et al. Gonorrhoea in inner London: results of a cross-sectional study. BMF 1997;314:1719-23

6 Hope V, MacArthur C. A comparison of HIV related advice in genitourinary medicine clinics with different histories. Genitourin Med 1996;72:286-9.

7 Department of Health. HIV and AIDS health promotion: an evolving strategy. London: DoH, 1995.

8 Hope V, MacArthur C. Acceptability of clinics for sexually ransmitted diseases among users of the 'gay scene' in the West Midlands. Genitourin Med 1997;73:299-302.

9 PMA/NHS Executive West Midlands. Sensitive purchasing: sexual health treatment and care issues for black and minority ethnic communities. Warwickshire: PMA, 1995.

10 Pillaye J. Preliminary results from a short patient survey of sexual health promotion in genitourinary medicine clinics. In: Pillaye J, ed. Sexual health promotion in genitourinary medicine clinics. London: Health Education Authority, 1994.

11 Department of Health, Public Health Laboratory Service, Institute of Child Health. Prevalence of HIV in England and Wales in 1996. Unlinked Anonymous Surveys Steering Group. Annual report of the Unlinked Anonymous Seroprevalence Monitoring Programme in England and Wales. London: Department of Health, December 1997. H17/0021273 1P, 1997.

2 Hope V, MacArthur C, Radcliffe K, et al. Promoting sexual health in relation to hiv: a preliminary study to investigate the provision of information and advice by the GUM service. Edgbaston: University of Birmingham, 1996.

13 AIDS and HIV infection in the United Kingdom: monthly report. CDR 1997;7:389-92.

14 Silverman D, Perakyla A, Bor R. Discussing safer sex in HIV counselling: assessing three communication formats. AIDS Care 1995;4:69-82.

15 Evens D, Farquhar C. An interview based approach to seeking users views in genitourinary medicine. Genitourin Med 1996;72:223-6. 